the economy is slowing down; thus, employment of these graduates will become more challenging. Second, high priority has to be attached to raising higher education quality. This needs more quality inputs including more state appropriation, strengthening faculty development, enhancing accreditation, and total quality management and evaluation programs. Third, the institutional isomorphism has to be changed through adjusting the structure of higher education, according to labor market demand by appropriately differentiating the institutions into different levels and different types, with each serving different human resources needs of the society. Fourth, for information technologies they should widely share the high-quality educational resources, such as making on-line courseware of the best teachers for nationwide use. Fifth, promote international exchanges and cooperation, and assimilate high-quality programs, such as Shanghai New York University.

\section{The Challenge of Graduate Unemployment in Africa}

\section{Goolam Mohamedbhal}

Goolam Mohamedbhai is former secretary general of the Association of African Universities. E-mail: g_t_mobhai@yahoo.co.uk.

Sub-Saharan Africa is the region with the lowest higher education enrollment-barely 8 percent. Conscious of the importance of higher education for socioeconomic development and in response to the ever-increasing demand for higher education, African countries have made huge efforts-in spite of many constraints and challenges-in increasing access to higher education. Enrollment in most countries has increased by several folds. The outcome was as expected-the greater output of graduates. Perhaps not expected was the increasing unemployment of these graduates, and this is true for almost every African country. In some countries, the unemployment figure is alarming. The social and political consequences of large unemployment, especially among the educated youth, can be serious, as evidenced by the 20II "Arab spring" in North Africa.

The causes of graduate unemployment are known. First, in concentrating on increasing access-but with inadequate financial, physical, and human resources-public universities have sacrificed quality for quantity. This has had a direct impact on the qualifications awarded. But more than good qualifications, employers look for attributes and competencies referred to as "soft skills"-these are quasi inexistent in the graduates. Also, the linkages between the university and the community-business and industry, public bodies, and the rural areas-are poor, and the university in many ways is cut off from the world of work.

But not all the causes can be laid at the doorstep of institutions. Other stakeholders have an equal share of responsibility. The private sector, which is fast becoming the main employer of graduates, must assist by providing short student internships, graduate training, soft-skills training and even funding as part of its social responsibility. The largest private companies in Africa are foreign owned and they must give priority to employing locally trained graduates.

Most countries also lack a differentiated higher education system that produces a diversified workforce in response to Africa's development priorities. African governments have, often for political reasons, replicated existing institutions or upgraded polytechnics and postsecondary colleges to universities, basically creating "more of the same" institutions. Yet, the labor market demand is more for lower-level, practically trained diploma holders than for academically-qualified degree holders.

Africa is currently the fastest growing region in the world, both economically and demographically. It has the world's youngest population, with huge expectations for education. The region needs highly skilled human capital for its sustained economic growth, so it must continue to expand its higher education sector. But development cannot be achieved by merely producing large numbers of graduates; it must be ensured that they are productively employed. Africa therefore needs to resolve its major challenge of graduate unemployment. What is needed in each African country is a concerted, well-defined strategy and action plan, at both national and institutional level. This strategy should also be motivated by reliable and up-to-date statistical data, which are severely lacking at present, to create a vibrant higher education sector can play its meaningful role in enabling Africa to overcome its development challenges and become a major pole of global growth.

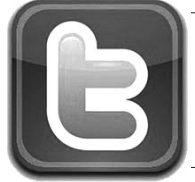
In addition to our Web site and Facebook page, we are now tweeting. We hope you will consider "following" us on Twitter! 